\section{Verônica Colpani'}

Poli Mara Spritzer'

Ana Paula Lodi"

Guilherme Gustavo Dorigo"

Isabela Albuquerque Severo de Miranda"

Laiza Beck Hahn"

Luana Pedroso Palludo"

Rafaela Lazzari Pietroski"

Karen Oppermann ${ }^{\prime \prime,}$, III

Unidade de Endocrinologia Ginecológica. Serviço de Endocrinologia. Hospital de Clinicas de Porto Alegre. Porto Alegre, RS, Brasil

- Faculdade de Medicina. Universidade de Passo Fundo. Passo Fundo, RS, Brasil

III Hospital São Vicente de Paulo. Passo Fundo, RS, Brasil

Correspondence:

Karen Oppermann

Rua Teixeira Soares 885/704

99010-081 Passo Fundo, RS, Brasil

E-mail: karenoppermann@gmail.com

Received: $2 / 6 / 2013$

Approved: 12/16/2013

Article available from: www.scielo.br/rsp

\section{Physical activity in climacteric women: comparison between self-reporting and pedometer}

\begin{abstract}
OBJECTIVE: To compare two methods of assessing physical activity in pre-, peri- and postmenopausal women.

METHODS: Cross-sectional study nested in a cohort of pre-, peri- and postmenopausal women in a city in Southern Brazil. The participants completed a questionnaire that included sociodemographic and clinical data. Physical activity was assessed using a digital pedometer and the International Physical Activity Questionnaire, short version. The participants were classified into strata of physical activity according to the instrument used. For statistical analysis, the Spearman correlation test, Kappa index, concordance coefficient and Bland-Altman plots were used.
\end{abstract}

RESULTS: The concordance $(\mathrm{k}=0110 ; \mathrm{p}=0.007)$ and the correlation (rho $=0.136, \mathrm{p}=0.02$ ) between the International Physical Activity Questionnaire, short version, and pedometer were weak. In Bland-Altman plots, it was observed that differences deviate from zero value whether the physical activity is minimal or more intense. Comparing the two methods, the frequency of inactive women is higher when assessed by pedometer than by the International Physical Activity Questionnaire - short version, and the opposite occurs in active women.

CONCLUSIONS: Agreement between the methods was weak. Although easy to use, Physical Activity Questionnaire - short version overestimates physical activity compared with assessment by pedometer.

DESCRIPTORS: Climacteric. Menopause. Motor Activity. Walking. Questionnaires, utilization. Cross-Sectional Studies. 


\section{INTRODUCTION}

Being sedentary has been recognized as a significant risk factor in developing cardiovascular disease (CVD), type 2 diabetes, metabolic syndrome and some types of cancer. ${ }^{13}$ The lack of physical activity (PA) is an important cause of avoidable death from non-communicable chronic disease.

Different instruments are available to evaluate PA and energy expenditure. Of the methods and techniques available, questionnaires are often used. Two such have been translated and validated in Portuguese. The International Physical activity Questionnaire - long form (IPAQ-LF) and short form (IPAQ-SF), are those with the best conditions to be used, with good reproducibility, although validity has been shown to be low. ${ }^{13}$

Another way of assessing PA is using a pedometer, a mechanical counter that records movement in response to the body's vertical acceleration. It is attached to the individual's waist, counting the number of steps taken. It enables occupational, leisure, domestic and transport activities to be measured cumulatively, and is a sensitive and objective method for quantifying an individual's PA. ${ }^{4}$

There are few studies of middle-aged women comparing habitual PA as measured using the IPAQ-SF or a pedometer. ${ }^{5}$ The aim of this study is to compare methods of assessing physical activity in pre-, peri- and post-menopausal women.

\section{METHODS}

This was a population-based cross-sectional study, nesting a cohort of pre-, peri- and post-menopausal women in the city of Passo Fundo, RS, Southern Brazil, from 2010 to 2011.

This cohort began in 1995, when 298 women were randomly selected to evaluate the prevalence of menopause symptoms, hormone levels and ultrasound pelvic measurements. ${ }^{16}$ In 2001, a second follow up was conducted, locating participants in the previous sample. Bearing in mind sample losses and population increase, new participants were included, randomly selected in the same way, ${ }^{1,8}$ giving a total sample of 358 pre-, periand post-menopausal women aged between 36 and 62 .

In 2010, to discover the participants' current state of health and cardiovascular risk, a third follow up was conducted. Participants were located using addresses, telephone numbers, hospital records, addresses of relatives and local radio and television, resulting in 301 women being contacted. Of these, complete data on PA level was obtained for 292, with nine being excluded due to cognitive difficulties (4), illiteracy (1) and errors recording the number of steps (4). ${ }^{4}$
Sociodemographic data, such as age, schooling (years at school), menopausal symptoms and hormone therapy (HT) were collected using a previously tested questionnaire. ${ }^{1,8}$ The work variable was evaluated using the question: “Are you currently in work?". Menopausal status was defined based on menstrual cycle characteristics and length of time of amenorrhea: pre-menopausal was defined as having a normal menstrual cycle at the time of the study; peri-menopausal was defined as experiencing changes in menstrual cycle frequency or flow in the 12 months before the study, and post-menopausal was defined as 12 months or more of natural or bilateral oophorectomy amenorrhea. A category called "hysterectomy" was created for women who had undergone hysterectomies without bilateral oophorectomy, and whose menopausal status could not be classified. Alcohol consumption was determined based on participant self-reporting of alcohol intake (do not drink, used to drink, drink). ${ }^{4,8}$ Participants also self-reported smoking habits categorized as: smoker, ex-smoker and non-smoker. Anthropometric data were collected in duplicate and included weight, height, waist circumference and waist to hip ratio. ${ }^{4}$

PA was evaluated using the IPAQ-SF questionnaire and counting number of steps taken according to the pedometer. In the IPAQ-SF, PA was classified in two ways: according to the number of minutes of PA in the week (inactive $<150 \mathrm{~min} \mathrm{PA} /$ week and active $\geq 150 \mathrm{~min} \mathrm{PA} /$ week $)^{1}$ and also by metabolic equivalent minutes per week (inactive $<600 \mathrm{MET} / \mathrm{min} /$ week, moderate from 600 to $1,499 \mathrm{MET} /$ $\mathrm{min} /$ week and active $\geq 1,500 \mathrm{MET} / \mathrm{min} /$ week $){ }^{17}$

The digital pedometer (model BP 148 TECHLINE) was used for seven consecutive days. Participants were instructed how to use the sensor properly and not to alter their typical activities during the study. They were instructed to note the number of steps in a diary at the end of each day. The mean number of steps was calculated by the ratio between the sum of the daily totals and the number of days the pedometer was used.

Using these measurements, the women were classified as inactive $(<6,000$ steps daily) and active $(\geq 6,000$ steps daily $)^{4}$ and the women were further classified as active ( $\geq 10,000$ steps daily), moderately active (between 5,000 and 9,999 steps daily) and inactive or sedentary $\left(<4,999\right.$ steps daily).$^{19}$ These two classifications were used in different analyses. The data were compared in $150 \mathrm{~min} /$ week (widely used and recommended by the World Health Organization) versus $\geq 6,000$ steps/ day (categorization already used with the same population in the previous study $)^{4}$ for dichotomous analysis. Correlation between energy expended in MET/ $\mathrm{min} /$ week (unit of measurement described in the IPAQ Directives for Processing and Analyzing Data) versus the three categories (sedentary, moderately active and active) used in the general population. ${ }^{19}$ 
The data analysis was performed using descriptive statistics to calculate the means, standard deviation and relative (\%) and absolute (n) frequencies. The percentage of women classified as active, moderately active and inactive using the two methods was compared using McNemar's Chi-square test to verify equality between the percentages of responses to level of physical activity. A dichotomous variable referring to concordance between the two instruments was created and the association between age, menopausal status and years of schooling was assessed using the Chi-square test. Spearman's rho was also used to analyze association between the mean number of steps, minutes of PA/week and MET/min/week. The Kappa (k) value, coefficient of concordance $(\mathrm{CC}, \%)$ and analysis of continuous measures using the methodology proposed by BlandAltman $^{2}$ were used to analyze concordance between the IPAQ-SF and the pedometer. This plotting enabled concordance between the two variables $(\mathrm{X}, \mathrm{Y})$ to be evaluated and to evaluate bias (by how much the differences are distant from zero), error (dispersion of the points of difference around the means), outliers and trends. ${ }^{12}$

To use the Bland-Altman test, Z scores were calculated in both instruments so as to annul units, as the pedometer uses steps/day and the IPAQ-SF MET/min/week. The equation for calculating the $Z$ score was: $Z=(X-\mu) / S . D$, in which $\mathrm{Z}=\mathrm{Z}$ score; $\mathrm{X}=$ unadjusted individual score; $\mu=$ mean of the variables; S.D. = standard deviation of the variable. At this point, 18 individuals were excluded from analysis as they had not done more than 10 continuous minutes of PA and did not have the complete data necessary to calculate MET/min/week. The level of significance was $5 \%$ in all analyses. The Statistical Package for the Social Sciences SPSS 20.0 and Stata 7.0 were used for the analyses.

This study was approved by the Research Ethics Committee of the Faculty of Medicine, Universidade de Passo Fundo and of the Hospital São Vicente de Paulo (Process 2010/16929). Participants signed an informed consent form.

\section{RESULTS}

The sample was composed of middle-aged women, with a mean age of $57.11(\mathrm{SD}=5.36)$, and a mean 8.74 years of schooling $(\mathrm{SD}=4.48), 20.0 \%$ of whom reported having fewer than four years of schooling. Of those with low levels of schooling, more than $70.0 \%$ were in the inactive group. Regarding menopausal symptoms, $7.2 \%$ of patients were in the pre-menopause, $8.6 \%$ in the peri-menopause, $78.4 \%$ were post-menopausal and $5.8 \%$ had had hysterectomies. The prevalence of smokers was $19.2 \%$, and $18.0 \%$ were using HT. Body mass index was $28.3 \mathrm{~kg} / \mathrm{m}^{2}(\mathrm{SD}=7.1)$, with the majority of the sample being overweight or obese (Table 1). There was no association between schooling, menopausal status and
Table 1. Demographic and anthropometric characteristics of study participants in Passo Fundo, RS, Southern Brazil, 2010. $(\mathrm{N}=292)$

\begin{tabular}{|c|c|c|c|c|}
\hline Variable & $\mathrm{n}$ & $\%$ & Mean & SD \\
\hline Age (years) & - & - & 57.11 & 5.36 \\
\hline \multicolumn{5}{|l|}{ Schooling (years) } \\
\hline 0 to 4 & 58 & 19.9 & - & - \\
\hline 5 to 8 & 91 & 31.2 & - & - \\
\hline 9 to 11 & 85 & 29.1 & - & - \\
\hline$\geq 12$ & 58 & 19.9 & - & - \\
\hline In work (yes) & 129 & 44.2 & - & - \\
\hline Hormone therapy (yes) & 48 & 18.0 & - & - \\
\hline \multicolumn{5}{|l|}{ Menopausal status } \\
\hline Pre-menopause & 21 & 7.2 & - & - \\
\hline Peri-menopause & 25 & 8.6 & - & - \\
\hline Post-menopause & 229 & 78.4 & - & - \\
\hline Hysterectomy & 17 & 5.8 & - & - \\
\hline \multicolumn{5}{|l|}{ Marital status } \\
\hline Married & 150 & 51.4 & - & - \\
\hline Single & 51 & 17.5 & - & - \\
\hline Separated/Divorced & 91 & 31.1 & - & - \\
\hline \multicolumn{5}{|l|}{ Alcohol consumption } \\
\hline Drinks alcohol & 96 & 32.9 & - & - \\
\hline Used to drink & 19 & 6.5 & - & - \\
\hline Does not drink & 177 & 60.6 & - & - \\
\hline \multicolumn{5}{|l|}{ Smoking } \\
\hline Smoker & 56 & 19.2 & - & - \\
\hline Ex-smoker & 67 & 22.9 & - & - \\
\hline Non smoker & 169 & 57.9 & - & - \\
\hline Overweight/obese (yes) & 198 & 68.3 & - & - \\
\hline BMI (kg/m2) & - & - & 28.3 & 7.0 \\
\hline Waist (cm) & - & - & 91.3 & 13.7 \\
\hline
\end{tabular}

BMI: body mass index

age and concordance between the two instruments ( $\mathrm{p}=$ $0.191, \mathrm{p}=0.268$ and $\mathrm{p}=0.619$, respectively).

Concordance between the two instruments, evaluated using the Kappa coefficient, was poor (steps/day and PA $\mathrm{min} /$ week, $\mathrm{k}=0.110 ; \mathrm{p}=0.007$ and steps/day and MET/ $\mathrm{min} / \mathrm{week}, \mathrm{k}=0.075 ; \mathrm{p}=0.013$ ). The $\mathrm{CC}$ as $47.0 \%$ (number of steps and PA min/week) and 32.0\% (number of steps and $\mathrm{MET} / \mathrm{min} /$ week), resulting in an intermediate value, considered poor concordance (Table 2).

Correlation, evaluated using Spearman's test, was significant, although weak (mean steps/day and MET/min/ week, rho $=0.113 ; \mathrm{p}=0.025$ ) (Figure, A). Figure $(\mathrm{B})$ shows the Bland-Altman graph, in which it can be seen that the majority of observations are within the $95 \%$ concordance level ( $\pm 1.96 \mathrm{SD})$ and that the mean difference in the $\mathrm{Z}$ score of both tests was close to zero. However, it was observed that the differences were distant from zero both when PA was minimal and when it was more intense. 
Table 2. Strata of physical activity in pre-, peri- and post-menopausal women, using the IPAQ-SF and pedometer, MET/min/ week versus steps per day. $(\mathrm{N}=292)$

\begin{tabular}{|c|c|c|c|c|c|c|c|}
\hline \multirow[t]{2}{*}{ Variable } & \multicolumn{2}{|c|}{$\begin{array}{c}\text { Inactive } \\
<4,999 \text { steps/day; } \\
<600 \mathrm{MET} / \mathrm{min} / \text { week }\end{array}$} & \multicolumn{2}{|c|}{$\begin{array}{c}\text { Moderate } \\
5,000 \text { to } 9,999 \text { steps/day } \\
600 \text { to } 1,499 \mathrm{MET} / \mathrm{min} / \text { week }\end{array}$} & \multicolumn{2}{|c|}{$\begin{array}{c}\text { Active } \\
\geq 10,000 \text { steps/day; } \geq \\
1,500 \mathrm{MET} / \mathrm{min} / \text { week }\end{array}$} & \multirow[t]{2}{*}{ Kappa $^{a}$} \\
\hline & $\mathrm{n}$ & $\%$ & $\mathrm{n}$ & $\%$ & $\mathrm{n}$ & $\%$ & \\
\hline Number of steps (pedometer) & 199 & 68.2 & 72 & 24.7 & 21 & 7.2 & 0.075 \\
\hline MET/min/week (IPAQ-SF) & 59 & 20.2 & 133 & 45.5 & 100 & 34.2 & \\
\hline
\end{tabular}

IPAQ-SF: International Physical Activity Questionnaire - short form

McNemar's Chi-square test, $p \leq 0.001$

${ }^{a}$ Kappa coefficient $p \leq 0.05$

Tables 2 and 3 show the frequency of participants in each strata of PA according to the two instruments used. There was a significant difference between the women classified in different strata of PA, with Kappa coefficients of 0.075 and 0.110 , respectively.

\section{DISCUSSION}

The number of women classed as active was at least twice as high when classified by the IPAQ-SF compared with when evaluated using a pedometer, for both the $\mathrm{MET} / \mathrm{min} /$ week and the PA/week criteria.

The results show that data referring to the PA strata obtained using the IPAQ-SF are not similar to those assessed in an objective way, using a pedometer. The BlandAltman findings corroborate Tables 2 and 3 , showing the frequency of inactive women is greater when assessed using a pedometer than using the IPAQ-SF, and the opposite is true for active women. The data indicate that the IPAQ-SF overestimates compared with the pedometer, principally in the active category.

A recent systematic review of the IPAQ-SF validity showed studies in populations in a similar age range to that of this study and which reported low to moderate correlation between the two methods. ${ }^{13}$ Studies comparing pedometer use and the IPAQ-SF stand out, such as that by De Cocker et al, ${ }^{6}$ with 310 healthy adults, reporting low to moderate correlation (PA total rho $=$ 0.28 ), and the study by Deng et al, ${ }^{7}$ with a sample of the Chinese population with a mean age of 65 , and moderate correlation $(\mathrm{PA}$ total $\mathrm{rho}=0.33 ; \mathrm{p}<0.001)$ between the two methods.

A Brazilian study of 21 post-menopausal women with osteoporosis assessed concordance between the IPAQ-LF and the pedometer. According to the IPAQ, $71.4 \%$ of participants were classified as active and $28.6 \%$ sedentary. The concordance between the IPAQ and the pedometer had a Kappa of 0.21..$^{5}$ Although the study sample used post-menopausal women and the long form IPAQ, it also found poor correlation between reported PA and direct evaluation using the pedometer. This study confirms these findings using the IPAQ-SF, although with a larger, representative sample of pre-, peri- and post-menopausal women.

The majority of women studied were middle-aged, did not work, were overweight or obese, had central adiposity, high blood pressure and were predominantly inactive when assessed using the pedometer. ${ }^{4}$ This profile of cardiovascular risk is strongly linked to sedentarism and reinforces that evaluating PA using a pedometer may be appropriate, on the other hand. Participants who walked more than $\geq 6,000$ steps/day had less central adiposity, metabolic syndrome or diabetes. ${ }^{4}$

In this study, pedometers were used for seven consecutive days, and a difference was noted in the number of steps taken according to the day of the week, with more steps taken on working days and in the summer. ${ }^{4}$ Studies suggest that using a pedometer for fewer days, as long as Saturday or Sunday are included, is as reliable s weekly use. ${ }^{9,11,20,21}$ Using a pedometer to monitor

Table 3. Strata of physical activity in pre-, peri- and post-menopausal women, using the IPAQ-SF and pedometer, MET/min/ week versus steps per day. $(\mathrm{N}=292)$

\begin{tabular}{|c|c|c|c|c|c|}
\hline \multirow[t]{2}{*}{ Variable } & \multicolumn{2}{|c|}{$\begin{array}{c}\text { Inactive } \\
<6,000 \text { steps/day; } \\
<150 \mathrm{~min} / \text { week }\end{array}$} & \multicolumn{2}{|c|}{$\begin{array}{c}\text { Active } \\
\geq 6,000 \text { steps/day; } \\
\geq 150 \mathrm{~min} / \text { week }\end{array}$} & \multirow[t]{2}{*}{ Kappa } \\
\hline & $\mathrm{n}$ & $\%$ & $\mathrm{n}$ & $\%$ & \\
\hline Number of steps (pedometer) & 199 & 68.2 & 93 & 31.8 & 0.110 \\
\hline Min/week (IPAQ-SF) & 75 & 26.0 & 214 & 74.0 & \\
\hline
\end{tabular}

IPAQ-SF: International Physical Activity Questionnaire - short form

McNemar's Chi-square test, $p \leq 0.001$

${ }^{a}$ Kappa coefficient $p \leq 0.05$ 


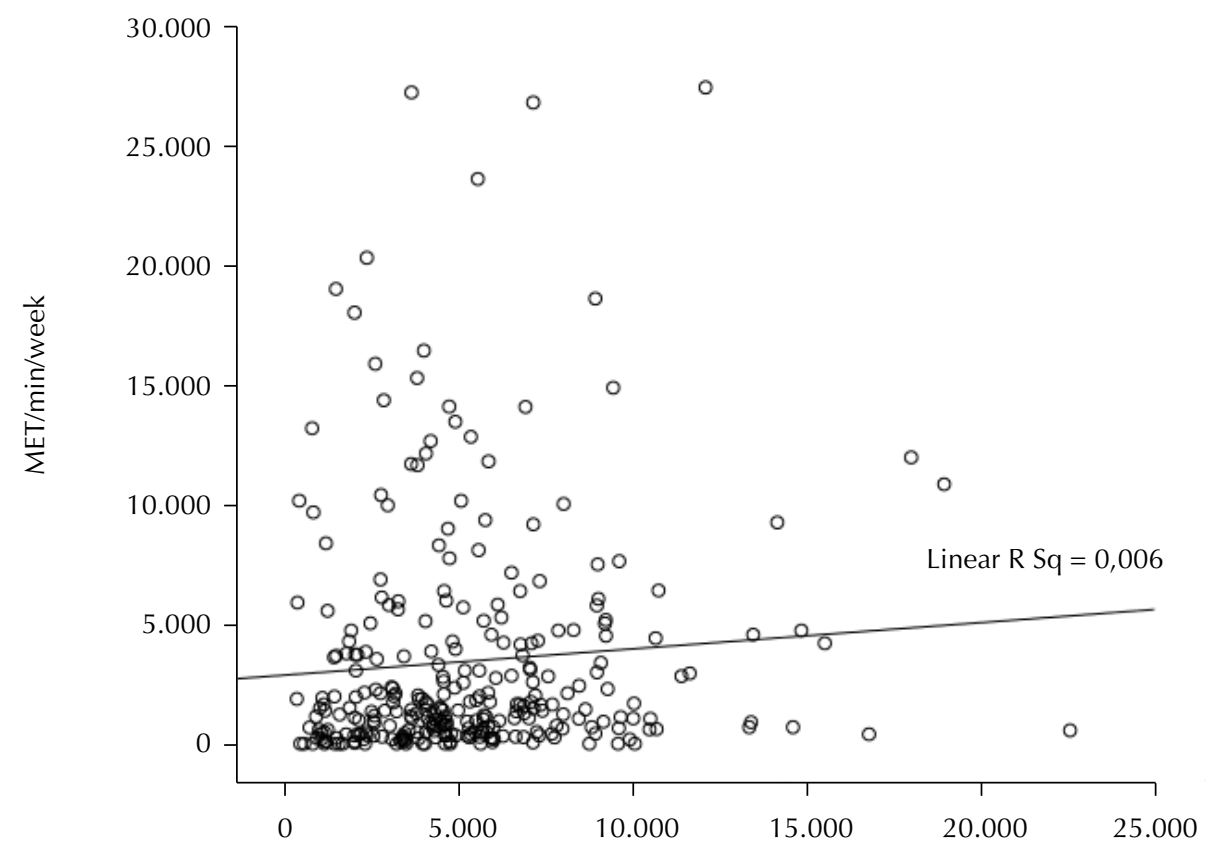

A.

Steps/day

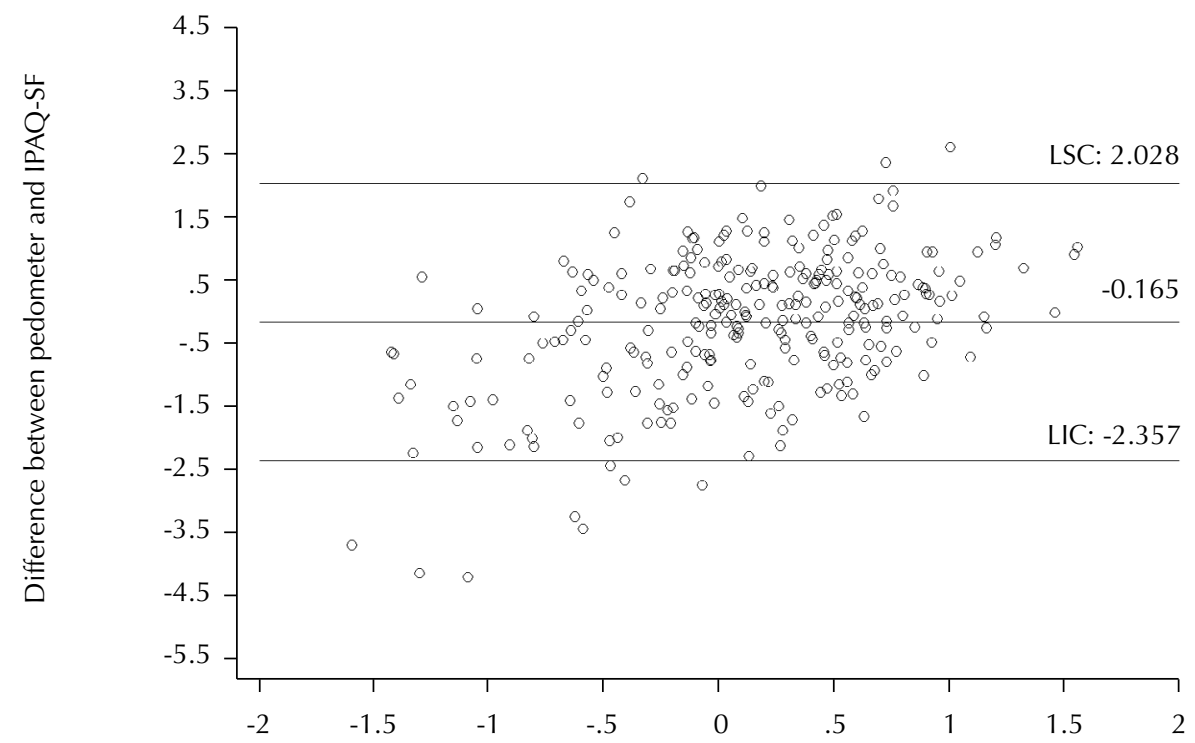

B.

Mean between pedometer and IPAQ-SF

ULC: Upper limit of concordance; LLC: Lower limit of concordance

A. Spearman's correlation ( $r$ ho $=0.113 ; p=0.025$ )

B. Bland-Altman test for concordance of measures of physical activity between the IPAQ-SF and the pedometer, mean Z score of steps/MET $(\log )$

Figure. Analysis of correlation and concordance in measures of physical activity between the International Physical Activity Questionnaire - short form and pedometer.

patients can take this form, increasing adherence due to ease of use and shorter intervention. Regardless, when evaluating PA longitudinally the use of the same instrument facilitates comparison of results.
The variability seen in the sample's level of schooling did not interfere in association or concordance between the pedometer and the IPAQ-SF, in contrast to what has been observed in another study, in which correlation 
between the two methods was a little greater after adjusting for sex, age and schooling. ${ }^{?}$

Regarding the instruments used, questionnaires are more accessible and allow the intensity and type of PA to be estimated. Their use may be preferred in long studies or those monitoring a large number of participants. On the other hand, it is a subjective method relying on memory, which may increase the chance of error. The concept of the 10 minute session and errors in perceiving intensity may lead to errors in interpreting and responding to the IPAQ-SF, ${ }^{10}$ although using interviewers to apply it helps to decrease this bias. The reliability of the IPAQ-SF means it can be used, with caution, in repetitive measure studies, there is no evidence corroborating its use as an absolute or relative measure of $\mathrm{PA} .{ }^{13}$

The pedometer is an objective method of evaluating PA. However, although it is a valuable tool in estimating and encouraging habitual and daily PA, it does not quantify movement on the horizontal and superior plane. ${ }^{3}$ It is appropriate for measuring travel (steps/ day) through the body's vertical oscillations, but it is not capable of evaluating activities such as cycling or any activity in water, and it does not discriminate type or intensity of PA.

Individuals accelerate, decelerate, stop and sit down many times in the course of a day while using a pedometer, and this may affect evaluation of energy expended and level of PA. North American adults show a variation in the time of repose or in the cadence (steps/min) throughout the day. There is a close relationship between cadence and walking speed, and 100 steps/min can be considered an appropriate estimate of a 3 MET activity. These estimates, however, cannot be considered as fixed values for total energy expenditure in a day. In this study, cadence was not measured individually, therefore, energy expenditure in MET cannot be used as a unit of measurement of the pedometer. ${ }^{22}$ Using an accelerometer would be a better alternative for comparing and converting energy expenditure evaluated by the IPAQ-SF and the distance covered by each participant. Some studies have shown moderate and strong correlation between figures obtained from the accelerometer and MET in adults, ${ }^{18}$ in contrast to other studies. ${ }^{13}$ The accelerometer method is more expensive and it is also unable to distinguish static activities (e.g., weight training), water sports or cycling, and there are still faults in correct and easy conversion and interpretation of the raw data produced from this instrument. ${ }^{14,15}$

A limitation of this study was the fact that the two instruments give results using different measures, which may limit the Bland-Altman analyses. However, calculating the $\mathrm{Z}$ score enables analysis between the tests.

This is the first Brazilian population-based study investigating these two methods of evaluating PA and relating them to menopausal status and schooling. The study design means the results can be transposed to similar populations.

Considering that habitual PA is an easily adopted behavior to prevent cardiovascular risk, it is essential that accurate methods of estimating it are used and that the instruments used can be considered of use in behavior modifying interventions encouraging PA.

To conclude, concordance between the IPAQ-SF and the pedometer was poor in the sample of menopausal women evaluated. Although easy to apply, the IPAQ-SF questionnaire overestimates PA compared to when assessed using a pedometer. 


\section{REFERENCES}

1. Bastos CA, Oppermann K, Fuchs SC, Donato GB, Spritzer PM. Determinants of ovarian volume in pre-, menopausal transition, and post-menopausal women: a population-based study. Maturitas. 2006;53(4):405-12. DOI:10.1016/j.maturitas.2005.07.002

2. Bland JM, Altman DG. Statistical methods for assessing agreement between two methods of clinical measurement. Lancet. 1986;327(8476):307-10. DOI:10.1016/S0140-6736(86)90837-8

3. Butte NF, Ekelund U, Westerterp KR. Assessing physical activity using wearable monitors: measures of physical activity. Med Sci Sports Exerc. 2012;44(1 Suppl 1):S5-12. DOI:10.1249/MSS.0b013e3182399c0e

4. Colpani V, Oppermann K, Spritzer PM. Association between habitual physical activity and lower cardiovascular risk in premenopausal, perimenopausal, and postmenopausal women: a populationbased study. Menopause. 2013;20(5):525-31. DOI:10.1097/GME.0b013e318271b388

5. Dallanezi GC, Corrrente JE, Freire BF, Mazeto GMFS. Concordância do International Physical Activity Questionnaire com o pedômetro, em mulheres pósmenopausadas portadoras de osteoporose. Rev Soc Bras Clin Med. 2011;9(2):93-6.

6. De Cocker KA, De Bourdeaudhuij IM, Cardon GM. What do pedometer counts represent? A comparison between pedometer data and data from four different questionnaires. Public Health Nutr. 2009;12(1):74-81 . DOI:10.1017/S1368980008001973

7. Deng HB, Macfarlane DJ, Thomas GN, Lao XQ, Cheng KK, Lam TH. Reliability and validity of the IPAQ-Chinese: the Guangzhou Biobank Cohort study. Med Sci Sports Exerc. 2008;40(2):303-7. DOI:10.1249/mss.0b013e31815b0db5

8. Donato GB, Fuchs SC, Oppermann K, Bastos C, Spritzer PM. Association between menopause status and central adiposity measured at different cutoffs of waist circumference and waistto-hip ratio. Menopause. 2006;13(2):280-5. DOI:10.1097/01.gme.0000177907.32634.ae

9. Graff SK, Alves BC, Toscani MK, Spritzer PM. Benefits of pedometer-measured habitual physical activity in healthy women. Appl Physiol Nutr Metab. 2012;37(1):149-56. DOI:10.1139/h11-145

10. Hallal PC, Gomez LF, Parra DC, Lobelo F, Mosquera J, Florindo AA, et al. Lessons learned after 10 years of IPAQ use in Brazil and Colombia. J Phys Act Health. 2010;7(Suppl 2):S259-64.
11. Hart TL, Swartz AM, Cashin SE, Strath SJ. How many days of monitoring predict physical activity and sedentary behaviour in older adults? Int J Behav Nutr Phys Act. 2011;8:62. DOI:10.1186/1479-5868-8-62

12. Hirakata VN CS. Análise de concordância entre métodos de Bland-Altman. Rev HCPA. 2009;29(3):261-8.

13. Lee PH, Macfarlane DJ, Lam TH, Stewart SM. Validity of the International Physical Activity Questionnaire Short Form (IPAQ-SF): a systematic review. Int I Behav Nutr Phys Act. 2011;8:115. DOI:10.1186/1479-5868-8-115

14. Matthew CE. Calibration of accelerometer output for adults. Med Sci Sports Exerc. 2005;37(11 Suppl):S512-22. DOI:10.1249/01.mss.0000185659.11982.3d

15. Murphy SL. Review of physical activity measurement using accelerometers in older adults: considerations for research design and conduct. Prev Med. 2009;48(2):108-14. DOI:10.1016/j.ypmed.2008.12.001

16. Oppermann K, Fuchs SC, Spritzer PM. Ovarian volume in pre- and perimenopausal women: a populationbased study. Menopause. 2003;10(3):209-13.

17. Ramirez-Marrero FA, Rivera-Brown AM, Nazario CM, Rodriguez-Orengo JF, Smit E, Smith BA. Self-reported physical activity in Hispanic adults living with HIV: comparison with accelerometer and pedometer. I Assoc Nurses AIDS Care. 2008;19(4):283-94. DOI:10.1016/j.jana.2008.04.003

18. Trost SG, Mclver KL, Pate RR. Conducting accelerometer-based activity assessments in field-based research. Med Sci Sports Exerc. 2005;37(11 Suppl):S531-43. DOI:10.1249/01.mss.0000185657.86065.98

19. Tudor-Locke C, Bassett DR Jr. How many steps/day are enough? Preliminary pedometer indices for public health. Sports Med. 2004;34(1):1-8.

20. Tudor-Locke C, Burkett L, Reis JP, Ainsworth BE, Macera CA, Wilson DK. How many days of pedometer monitoring predict weekly physical activity in adults? Prev Med. 2005;40(3):293-8. DOI:10.1016/j.ypmed.2004.06.003

21. Tudor-Locke C, Craig CL, Brown WJ, Clemes SA, De Crocker K, Giles-Corti B, et al. How many steps/day are enough? For adults. Int I Behav Nutr Phys Act. 2011;8:79. DOI:10.1186/1479-5868-8-79

22. Tudor-Locke C, Rowe DA. Using cadence to study free-living ambulatory behaviour. Sports Med. 2012;42(5):381-98. DOI:10.2165/11599170-000000000-00000

This study was partially supported by the Conselho Nacional de Desenvolvimento Científico e Tecnológico (CNPq) and by the Institutos Nacionais de Ciência e Tecnologia (INCT) de Hormônios e Saúde da Mulher (CNPq/INCT 573747/2008-3). The authors declare that there is no conflict of interest. 